\title{
Bilateral hydrothorax and cardiac tamponade after right subclavian vein catheterization
} -A case report-

\author{
Myoung Hwa Kim, Dong-Jun Lee, and Mun Chul Kim \\ Department of Anesthesiology and Pain Medicine, Seoul Paik Hospital, Inje University College of Medicine, Seoul, Korea
}

Central venous catheterization is typically used for the anesthetic management of patients undergoing a major surgery or care of patients in Intensive Care Unit (ICU). The occurrence of complications associated with central venous catheterization such as pneumothorax or vascular injury have decreased, while delayed complications such as hydrothorax, hydromediastinum, or cardiac tamponade have risen recently. We report a case of complications of bilateral hydrothorax with cardiac tamponade by superior vena cava perforation due to continuous mechanical force of the looped central venous catheter tip against SVC wall after subclavian vein cannulation. (Korean J Anesthesiol 2010; 59: S211-S217)

Key Words: Cardiac tamponade, Central venous catheterization, Hydromediastinum, Hydrothorax.

Central venous catheterization is a useful procedure for intraoperative hemodynamic monitoring, rapid intervascular injection, parenteral feeding and drug injection, as well as in cases where approaching the peripheral vessel is difficult due to peripheral vascular collapse. However, it can cause complications such as pneumothorax, vascular perforation, cardiac tamponade, hemomediastinum, hydrothorax, hemothorax, air embolism, intravascular thrombus and vascular injury. The occurrence of complications such as pneumothorax, hemothorax and vascular injury immediately following the procedure is gradually decreasing due to improvements in procedural techniques and equipment, including the material used in manufacturing central venous catheters $[1,2]$. However, as the need for long-term central venous catheterization increases for reasons such as total parenteral nutrition (TPN), the probability of delayedcomplications including hydrothorax, hydromediastinum and cardiac tamponade has not decreased [2-4]. For example, cardiac tamponade is found 24 hours after catheterization in $50 \%$ of patients who have had the complication $[5,6]$, and vascular perforation is found 3 days after the procedure in $41 \%$ of patients [2]. Thus, delayed complications following the procedure show high mortality due to late identification of the cause and diagnosis (e.g., mortality rate of cardiac tamponade ranges from 44-77\%) [5]. Though rare, several cases of ipsilateral hydrothorax [3], bilateral hydrothorax accompanied by hydromediastinum [4], and cardiac tamponade $[5,6]$ have been reported several times. However, simultaneous occurrence of bilateral hydrothorax

Received: January 4, 2010. Revised: 1st, January 26, 2010; 2nd, February 18, 2010. Accepted: April 5, 2010.

Corresponding author: Dong-Jun Lee, M.D., Department of Anesthesiology and Pain Medicine, Seoul Paik Hospital, Inje University College of Medicine, Jeo-dong 2-ga, Jung-gu, Seoul 100-032, Korea. Tel: 82-2-2270-0096, Fax: 82-2-2270-0094, E-mail: daidong@hanmail.net (c) This is an open-access article distributed under the terms of the Creative Commons Attribution Non-Commercial License (http:// creativecommons.org/licenses/by-nc/3.0/), which permits unrestricted non-commercial use, distribution, and reproduction in any medium, provided the original work is properly cited. 
and cardiac tamponade is extremely rare with only a few case reports [6-9]. Herein, we report a case of cardiac tamponade and bilateral hydrothorax after performing central venous catherization due to the catheter torsion and the abnormal location.

\section{Case Report}

A $58 \mathrm{~kg}, 164 \mathrm{~cm}$, 75-year-old female patient was hospitalized with a chief complaint of abdominal pain and fever. She was diagnosed with cholecystitis by choledocholithiasis, and though she was treated with percutaneous transhepatic biliary drainage, a cholecystectomy was performed because the disease had progressed to gallbladder empyema. There were no special findings in the patient's electrocardiogram, and peripheral blood test results were: Hemoglobin (Hb) $12.0 \mathrm{~g} /$ dl, Hematocrit (Hct) 32\%, platelet 203,000/ $\mu$ l, and leukocyte $4,270 / \mu \mathrm{l}$. Biochemical test results were:total protein $5.3 \mathrm{~g} / \mathrm{dl}$, albumin $2.9 \mathrm{~g} / \mathrm{dl}$, aspartate aminotransferase (AST) $53 \mathrm{IU} / \mathrm{L}$, alanine aminotransferase (ALT) $34 \mathrm{IU} / \mathrm{L}$, and total cholesterol $56 \mathrm{mg} / \mathrm{dl}$. Blood coagulation testresults were prothrombin time 14.1 seconds (58\%), activated partial thromboplastin time 37 seconds, and international normalized ratio (INR) 1.34 . Electrolyte test findings were natrium $134 \mathrm{mEq} / \mathrm{L}$, potassium $4.5 \mathrm{mEq} / \mathrm{L}$, and chloride $107 \mathrm{mEq} / \mathrm{L}$, while blood urea nitrogen (BUN) and creatinine were slightly elevated, (40 and $1.7 \mathrm{mg} /$ $\mathrm{dl}$, respectively). The patient had symptoms of coughing and a little sputum for 15 days before the visit, and the chest radiograph taken in the hospital also revealed pleural effusion and subsegmental atelectesis in both lower lobes of the lung (Fig. 1). The results of the arterial blood gas test carried out

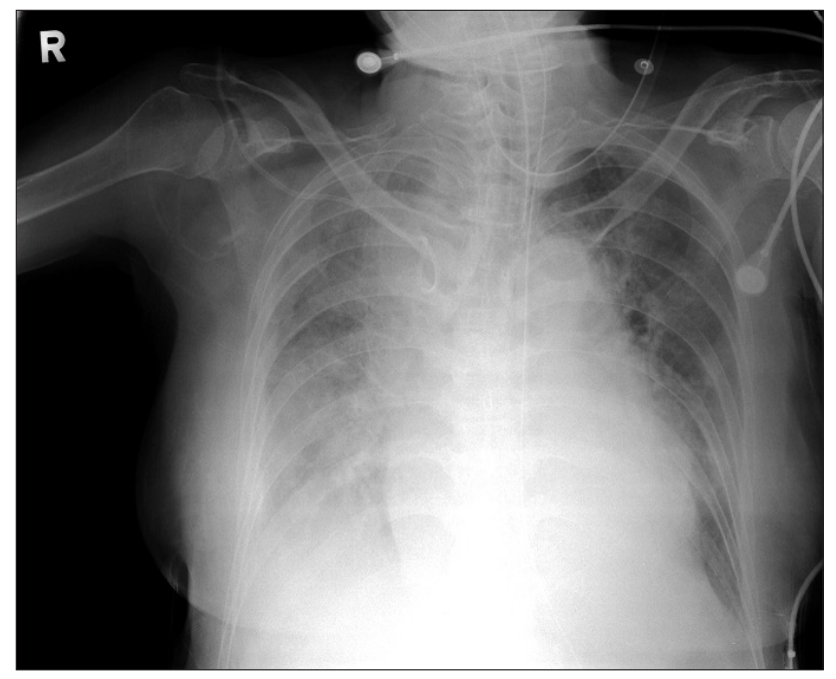

Fig. 1. Chest PA radiograph of a patient with minimal pleural effusion and subsegmental atelectasis in both lower lung fields. after the visit, with oxygen supply at $5 \mathrm{~L} / \mathrm{min}$ flow rate through nasal cannula, were: $\mathrm{pH} 7.48, \mathrm{PaCO}_{2} 26 \mathrm{mmHg}, \mathrm{PaO}_{2} 60 \mathrm{mmHg}$, $\mathrm{HCO}_{3}{ }^{-} 22.6 \mathrm{mmol} / \mathrm{L}, \mathrm{BE}-2.8 \mathrm{mmol} / \mathrm{L}$, and $\mathrm{O}_{2}$ saturation $(\mathrm{SaO})$ $92 \%$. Crackles were heard in both lower lobes of the patient's lung by auscultation; the patientwas treated with antibiotics. Results of the arterial blood gas test carried out 3 days after treatment commencement at dawn on the day of operation, without oxygen supply, were: $\mathrm{pH} 7.23, \mathrm{PaCO}_{2} 57 \mathrm{mmHg}, \mathrm{PaO}_{2}$ $93 \mathrm{mmHg}, \mathrm{HCO}_{3}{ }^{-} 21.5 \mathrm{mmol} / \mathrm{L}, \mathrm{BE}-4.4 \mathrm{mmol} / \mathrm{L}$, and $\mathrm{SaO}_{2}$ $96 \%$. The chest radiograph also showed that pleural effusion in both lower lobes of the lung was reduced and the subsegmental atelectesis was extended and improved. Given the patient's status, it was decided that an operation would be performed after informing the patient's caregiver that mechanical ventilation could be used even after the operation.

According to the patient's history, she had already had a back operation and hysterectomy, and had been treated with drugs after being diagnosed with high blood pressure and diabetes. For the diabetes, acarbose $100 \mathrm{mg}$, metformin $500 \mathrm{mg}$, and nateglinide $90 \mathrm{mg}$ had been taken. The glycated hemoglobin measurement before the operation was $6.9 \%$, and blood sugar test (BST) results were regulated to $203 \mathrm{mg} / \mathrm{dl}, 211 \mathrm{mg} / \mathrm{dl}$, and $244 \mathrm{mg} / \mathrm{dl}$. Additional insulin was to be injected if blood sugar level rose above $250 \mathrm{mg} / \mathrm{dl}$. BST increased to $307 \mathrm{mg} / \mathrm{dl}$ two days before the operation and $323 \mathrm{mg} / \mathrm{dl}$ one day before the operation; consequently, and 10 units of insulin were injected sequentially at dawn on the day of operation. No specific drug for high blood pressure was taken, but she had been taking aspirin to aid blood circulation. Vital signs at the ward were: systolic blood pressure 110-150 $\mathrm{mmHg}$, diastolic blood pressure $70-100 \mathrm{mmHg}$, heart rate $68-88 \mathrm{time} / \mathrm{min}$, and body temperature $36.8-37.5^{\circ} \mathrm{C}$.

Intramuscular glycopyrrolate $0.2 \mathrm{mg}$ was used as a preanesthetic medication. Vital signs of the patient upon arrival at the operation room were: blood pressure 140/85 $\mathrm{mmHg}$, heart rate 90 time/min, and pulse oxygen saturation measured by a pulse oximeter $95 \%$. Pulse oxygen saturation increased to $100 \%$ after preoperative oxygenation was performed with $5 \mathrm{~L}$ of oxygen supply. For the induction, an intravascular injection of propofol $80 \mathrm{mg}$ and rocuronium $50 \mathrm{mg}$ was used, and tracheal intubation with a 7.0 mminner diameter tube followed after loss of consciousness muscle relaxation sufficiently progressed. The tracheal intubation was followed by mechanical ventilation with tidal volume of $9 \mathrm{ml} / \mathrm{kg}$ and a minute tidal rate of 10 . Anesthesia was maintained with oxygen $2.5 \mathrm{~L} / \mathrm{min}$, medical air $2.5 \mathrm{~L} / \mathrm{min}$, remifentanil $0.21 \mu \mathrm{g} / \mathrm{kg} / \mathrm{min}$, propofol $86 \mu \mathrm{g} / \mathrm{kg} / \mathrm{min}$, and atracurium $7 \mu \mathrm{g} / \mathrm{kg} / \mathrm{min}$. For continuous blood pressure measurement and blood test, a 22-gauge catheter was inserted into the right radial artery. Considering long-term postoperative drug injection and total parenteral nutrition in the ward, it was 
decided that 7 Fr Two-lumen Central Catheterization Set with Arrow gard Blue (Arrow international Inc., PA, USA) should be inserted into the subclavian vein. After putting the patient in the Trendelenburg position, turning the patient's neck to the left side, touching the right arm to the body and pulling it to the lower side, a pillow was inserted under the spine at the back of the shoulder so that the head of the humerus would not prevent needle entry. At the central part of the clavicle and $2 \mathrm{~cm}$ below the part where $2 / 3$ of the back clavicles meet together, skin puncture was carried out with an $18 \mathrm{G}, 6.35 \mathrm{~cm}$, thin-wall needle, which was advanced under the clavicle toward the sternal notch parallel with the clavicle, engaging weak negative pressure to the needle. In the first trial, the vein was punctured and no specific resistance was felt at the time of inserting the J-guide wire and dilator after venipuncture. 7 Fr Two-lumen Central Catheterization Set was inserted and fixed to the skin $15 \mathrm{~cm}$ deep after checking blood aspiration at the two catheters. Since no serious hemorrhaging was expected in the prearranged operation, the central venous pressure measuring kit was not connected and the fluid and drug were injected with the two catheters.

Immediately after operation commencement, blood pressure elevated to $170 / 95 \mathrm{mmHg}$; thus, $5 \mathrm{mg}$ and $10 \mathrm{mg}$ of labetalol as well as nitroglycerine were injected into the vein at a flow rate of $0.28 \mu \mathrm{g} / \mathrm{kg} / \mathrm{min}$ for 30 minutes to normalize blood pressure. Results from an arterial blood gas tester (Blood gas/electrolyte analyzer, GEM premier 3000 with $\mathrm{IQM}$, Instrumentation Laboratory, MA, USA) used immediately after the operation showed: $\mathrm{pH}$ 7.52, $\mathrm{PCO}_{2} 31 \mathrm{mmHg}, \mathrm{PO}_{2} 175 \mathrm{mmHg}, \mathrm{HCO}_{3}{ }^{-} 25.3 \mathrm{mmol} /$ $\mathrm{L}, \mathrm{Be}-2.5 \mathrm{mmol} / \mathrm{L}, \mathrm{SaO}_{2} 100 \%, \mathrm{Hb} 12.6 \mathrm{~g} / \mathrm{dl}$, and Hct 37\%, with no special findings. After stabilizing 1.5 hours after induction, blood pressure dropped to $95 / 65 \mathrm{mmHg}$. It was assumed that hypovolemia did not cause the drop because a total of 1,000 $\mathrm{ml}$ of fluid, including $500 \mathrm{ml}$ of crystalloid solution and 500 $\mathrm{ml}$ of colloid solution, was injected until that time, and the possibility of hemorrhaging was not particularly serious. Thus, dopamine was injected, increasing the quantity from $3 \mu \mathrm{g} / \mathrm{kg} /$ $\min$ to $5 \mu \mathrm{g} / \mathrm{kg} / \mathrm{min}$. Blood pressure, however, did not increase, so ephedrine was injected twice, (5 mg doses) increasing BP to $110 / 70 \mathrm{mmHg}$. During the continuous intravascular injection of dopamine at a rate of $5.5 \mu \mathrm{g} / \mathrm{kg} / \mathrm{min}$, systolic and diastolic BP stayed at $95-125 \mathrm{mmHg}$ and $55-70 \mathrm{mmHg}$, respectively. Arterial blood gas test results at that time were: $\mathrm{pH}$ 7.46, $\mathrm{PaCO}_{2}$ $30 \mathrm{mmHg}, \mathrm{PO}_{2} 142 \mathrm{mmHg}, \mathrm{HCO}_{3}{ }^{-} 21.3 \mathrm{mmol} / \mathrm{L}, \mathrm{BE}-1.7$ $\mathrm{mmol} / \mathrm{L}, \mathrm{SaO}_{2} 99 \%, \mathrm{Hb} 11.9$, Hct $35 \%$, and airway pressure was maintained at approximately $18 \mathrm{cmH}_{2} \mathrm{O}$.

Two hours after induction, maximum inspiratory pressure suddenly rose from 18 to $25 \mathrm{cmH}_{2} \mathrm{O}$. While checking airway management, crackles were auscultated. Assuming, the increased maximum inspiratory pressure was caused by an increased amount of discharge, aspiration with an endotracheal tube was attempted, but almost no discharge was found. Thus, the lungs expanded several times to a maximum inspiratory pressure of $30-40 \mathrm{cmH}_{2} \mathrm{O}$. After reducing tidal volume from 9 $\mathrm{ml} / \mathrm{kg}$ to $8 \mathrm{ml} / \mathrm{kg}$ and maintaining the minute tidal rate at $10 /$ min, maximum inspiratory pressure stayed at $22 \mathrm{cmH}_{2} \mathrm{O}$ at a slightly reduced level. Arterial blood gas test results at that time, with $\mathrm{FiO}_{2} 1.0$ were: $\mathrm{pH} 7.37, \mathrm{PCO}_{2} 39 \mathrm{mmHg}, \mathrm{PO}_{2} 248$ $\mathrm{mmHg}, \mathrm{SaO}_{2} 100 \%, \mathrm{HCO}_{3}{ }^{-} 22.5 \mathrm{mmol} / \mathrm{L}, \mathrm{BE}-2.5 \mathrm{mmol} / \mathrm{L}, \mathrm{Hb}$ 11.9, and Hct $35 \%$. A choledocholithotomy was being carried out after the cholecystectomy, checking the bleeding part and performing hemostasis without any particular problems. Despite intravascular injection of glycopyrrolate $0.2 \mathrm{mg}$ and pyridostigmine $10 \mathrm{mg}$, supplying $100 \%$ oxygen, and inducing spontaneous breathing post-operation, respiratory pattern was not uniform enough compared with the speed of the patient's consciousness recovery. As the patient's breathing was unstable and pulse oxygen saturation had dropped to $93 \% 30$ minutes after attempting spontaneous breathing, the patient was moved to the ICU immediately and supplied with oxygen without extubation. 1,150 ml of crystalloid solution, $500 \mathrm{ml}$ of colloidal solution, and $70 \mathrm{ml}$ of albumin were injected into the patient in the 2 hours and 45 minutes between induction and transport to the ICU. The expected hemorrhage was $800 \mathrm{ml}$ and urination was $150 \mathrm{ml}$, while he intraoperative BST was $179-231 \mathrm{mg} / \mathrm{dl}$.

Immediately after transport to the ICU, vital signs were: BP $111 / 70 \mathrm{mmHg}$, heart rate $89 / \mathrm{min}$, central venous pressure $5 \mathrm{cmH}_{2} \mathrm{O}$, and pulse oxygen saturation $93 \%$. The patient's breathing was managed by pressure support ventilation with $\mathrm{FiO}_{2}$ 0.7, tidal volume $550 \mathrm{ml}$, tidal rate $20 / \mathrm{min}$ and positive end expiratory pressure $8 \mathrm{cmH}_{2} \mathrm{O}$. Arterial blood gas analysis 30 minutes after transport to the ICU showed $\mathrm{pH}$ 7.34, $\mathrm{PCO}_{2}$ $38 \mathrm{mmHg}, \mathrm{PO}_{2} 82 \mathrm{mmHg}, \mathrm{SaO}_{2} 95 \%, \mathrm{HCO}_{3}{ }^{-} 20.5 \mathrm{mmol} / \mathrm{L}$, $\mathrm{BE}-4.8 \mathrm{mmol} / \mathrm{L}, \mathrm{Hb} 11.9$, and $\mathrm{Hct} 34 \%$. $\mathrm{FiO}_{2}$ was regulated to $0.5,30$ minutes later. Fluids, drugs, and total parenteral nutrition (COMBIFLEX PERI Inj.) were injected through the central venous catheter. The total parenteral nutrition was a hyperosmotic fluid ( $875 \mathrm{mOsm} / \mathrm{L})$; consequently, it was injected slowly for 24 hours. From the chest radiograph taken at that time, the pneumonia finding was continued at the right lung accompanied by pleural effusion. Though a loop of the central venous catheter was observed in the superior vena cava, the location of the catheter was not corrected but just monitored, since the total vascular parenteral nutrition, fluid and drug were being injected smoothly. Three hours after transport to the ICU, $\mathrm{BP}$ was 150/65 mmHg and heart rate $70 / \mathrm{min}$. While maintaining pressure support ventilation with $\mathrm{FiO}_{2} 0.5$, tidal volume 500 $\mathrm{ml}$, minute tidal rate 18 , and positive end expiratory pressure $6 \mathrm{cmH}_{2} \mathrm{O}$, the patient continuously attempted spontaneous breathing. Since the results of the arterial blood gastest were 
pH 7.41, PCO $234 \mathrm{mmHg}, \mathrm{PO}_{2} 69 \mathrm{mmHg}, \mathrm{SaO}_{2} 94 \%, \mathrm{HCO}_{3}{ }^{-}$ $21.6 \mathrm{mmol} / \mathrm{L}$, and $\mathrm{BE}-2.4 \mathrm{mmol} / \mathrm{L}$, the patient got out of the mechanical ventilation. Because spontaneous breathing continued and after that and pulse oxygen saturation stayed at 97\% continuously as 5 liters of oxygen were provided through T-piece for more than an hour, the patient was extubated. However, 6 hours after extubation, BP suddenly dropped to $80 / 45 \mathrm{mmHg}$, therefore dopamine was injected at a rate of 12 $\mu \mathrm{g} / \mathrm{kg} / \mathrm{min}$ to elevate BP. The patient was then re-intubated because her respiratory rate had increased to $28-32 / \mathrm{min}$, showing respiratory distress. Arterial blood gas test performed with a $7 \mathrm{~L} / \mathrm{min}$ oxygen supply through an oxygen mask showed these, $\mathrm{pH} 7.26, \mathrm{PCO}_{2} 52 \mathrm{mmHg}, \mathrm{PO}_{2} 98 \mathrm{mmHg}, \mathrm{SaO}_{2}$ $97 \%, \mathrm{HCO}_{3}{ }^{-} 23.3 \mathrm{mmol} / \mathrm{L}$, and $\mathrm{BE}-3.8 \mathrm{mmol} / \mathrm{L}$, indicating respiratory acidosis. Mechanical respiration was continued with pressure support ventilation of $\mathrm{FiO}_{2} 0.55$, tidal volume 400 $\mathrm{ml}$, and minute tidal rate 18 , and pulse oxygen saturation was maintained above $95 \%$. Continuous tracking and monitoring of chest radiographs showed more serious pneumonia accompanied by pleural effusion in the right and left lungs, which was assumed to be the result of the preoperative pneumonia, deteriorating to pleural effusion. Twenty four hours after the end of the operation, the patient complained of respiratory distress even though oxygen saturation was under pressure support ventilation at tidal volume $500 \mathrm{ml}$, minute tidal rate 14, positive end expiratory pressure $4 \mathrm{cmH}_{2} \mathrm{O}$, and $\mathrm{FiO}_{2} 0.6$ at $94-98 \%$, and systolic BP dropped below $90 \mathrm{mmHg}$. Therefore, dopamine intravascular injection was continuously carried out at a rate of $15 \mu \mathrm{g} / \mathrm{kg} / \mathrm{min}$, however vital signs were unstable with $\mathrm{BP}$ at $80 / 50 \mathrm{mmHg}$ and heart rate at 130 / min. At that time, 2,000 $\mathrm{ml}$ of crystalloid solution, $400 \mathrm{ml}$ of

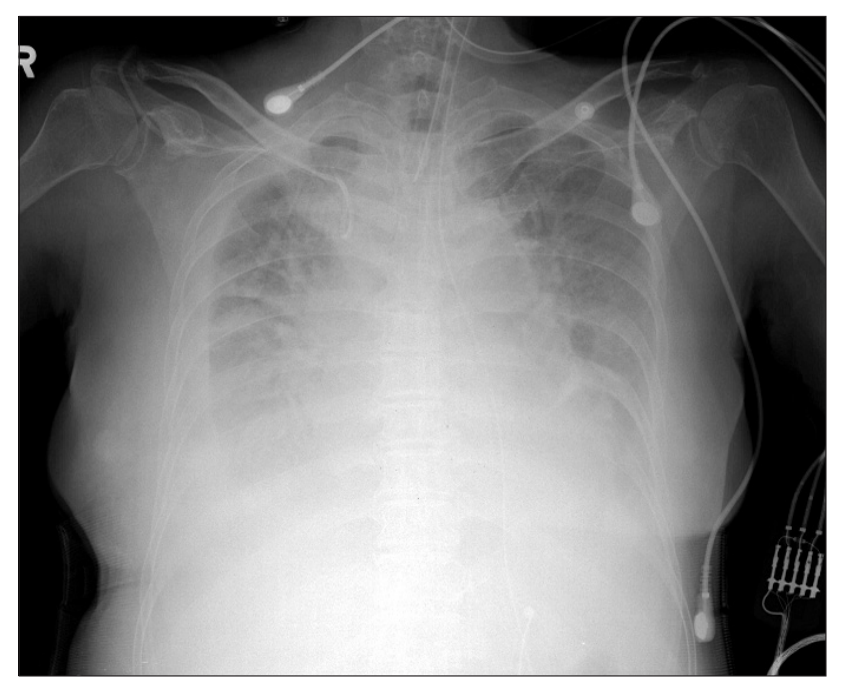

Fig. 2. Chest AP radiograph at the postoperative 1 day. This shows that central venous catheter tip is looped slightly in SVC and increased pleural effusion is in both lungs, especially RUL, RLL. colloid solution, and $250 \mathrm{ml}$ of total parenteral nutrition had been already injected through the central venouscatheter. Although a total of $45 \mathrm{mg}$ of furosemide was injected 4 times, continuously increasing pleural effusion was found in the lower parts of both lungs in follow-up chest radiographs (Fig. 2). The echocardiography performed due to unstable vital signs showed pericardialeffusion of approximately $1 \mathrm{~cm}$. Though the thoracentesis and pericardiocentesis were carried out to drain the effusionfluid, $100 \mathrm{ml}$ of milky pleural effusion fluid was drained from the right side of the thorax, $760 \mathrm{ml}$ of bright lemon-colored serous pleural effusion fluid from the left side, and $30 \mathrm{ml}$ of bright lemon-colored serous pericardial effusion fluid from the pericardium. Immediately after it was verified that the color and properties of the pleural effusion fluid and pericardial effusion fluid were similar to the total parenteral nutrition that had been injected into the patient, aspiration through the central venous catheter was carried out. Blood was refluxed in the proximal but not the distal catheter. Surmising that the abnormal location of the cardiac vein catheter terminal caused the hydrothorax and cardiac tamponade, the central venous catheter was removed 30 hours after installation, and a central venous catheter was newly installed through the internal jugular vein on the opposite site.

After removal of the central venous catheter, pleural and pericardial effusion fluid were continuously drained. Vital signs gradually stabilized, respiratory distress was also relieved, and follow-up chest radiograph showed the pleural effusion was gradually improving. The echocardiography performed four days after the pericardiocentesis showed the pericardial effusion almost disappeared. Since the chest radiograph revealed the pleural effusion had almost disappeared (Fig. 3)

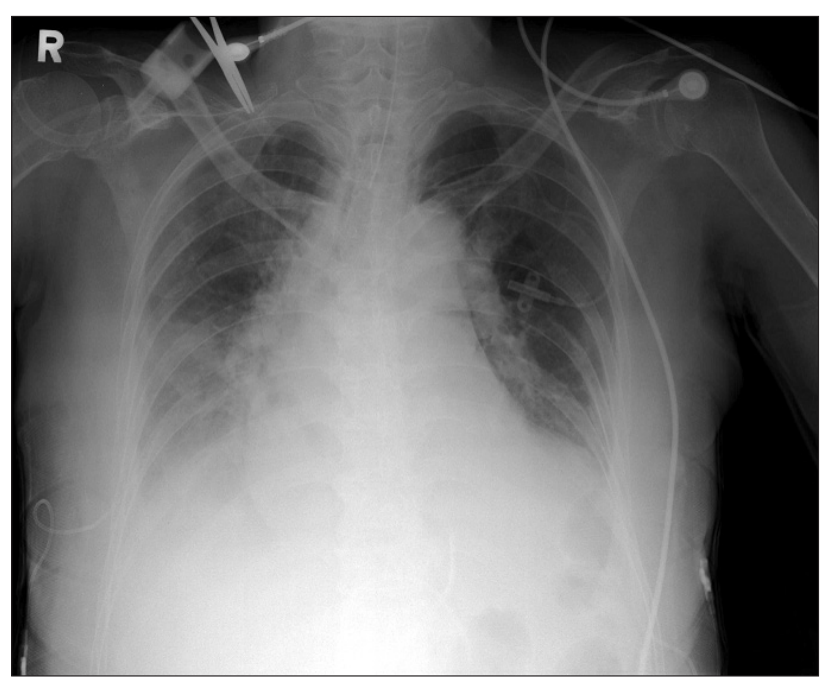

Fig. 3. Chest AP radiograph taken after thoracentesis and pericardiocentesis shows improved pleural effusion at the postoperative 6 days. 
and spontaneous breathing was well maintained for 6 days following the operation, the patient was extubated. A total of $320 \mathrm{ml}$ of pleural effusion fluid was drained from the right side of the thorax, 1,480 $\mathrm{ml}$ from the left side, and $340 \mathrm{ml}$ from the pericardium. The BST performed in the ICU was $200-300 \mathrm{mg} /$ $\mathrm{dl}$, on average. As in the preoperative period, diabetes treatment was continued assuming that additional insulin would be injected into the patient if blood sugar rose above $250 \mathrm{mg} / \mathrm{dl}$. After that the patient's status continuously improved, and she was moved to the general ward and eventually discharged on the 19th day after the operation without any complications.

\section{Discussion}

Central venous catherization is a procedure generally applied not only to intraoperative care but also to postoperative care including total parenteral nutrition (TPN). As the number of patients who need long-term installation of central venous catheters increases, the occurrence of delayed complicationsincluding hydrothorax, hydromediastinum, and cardiac tamponade-is also increasing [2-4]. Twenty nine percent of delayed cardiac tamponade caused by central venous catheterization are found within 24 hours, $12 \%$ between 23 hours and 38 hours, $31 \%$ between 48 hours and 7 days, and $18 \%$ after 7 days [6], and results from puncturing of the heart and superior vena cava by the terminal of the central venous catheter $[5,10]$. Hydrothorax is caused by venipuncture of the central venous catheter terminal [5] or its placement in the mediastinum [1]. Symptoms of such complications include sudden respiratory distress, tachypnea, cyanosis of the entire body, reduced blood pressure, and tachycardia $[2,7]$. Respiratory distress of our patient did not progress but rather improved after she was moved to the ICU post-operation however, symptoms of respiratory distress and reduced blood pressure were found 6 hours later, which was judged as a complication due to delayed blood vessel injury. Major factors related to similar blood vessel wall injuries caused by central venous catheters are the location of the central venous catheter terminal $[1,5,10]$, types of fluids $[3,4,11]$ and the material of the central venous catheter [2]. Ideally, the terminal of the central venous catheter should be located parallel to the blood vessel wall in the superior vena cava and placed at the lower part of the bottom line of the clavicle, and the level of the third costa, i.e. the space in between the no. 4 and no.5 thoracic vertebra and the azygos vein and carina or the branch point of the right main bronchus [12]. If the central venous catheter is located in only the superior vena cava, central venous pressure measurement can be inaccurate and the risk of thrombophlebitis and blood vessel erosion increases [11]. Depending on reports, frequency of abnormal location of the central venous catheter is $6.2 \%$ from all central venous catheterizations. Abnormal location when approaching through the subclavian vein was $9.3 \%$, while abnormal location frequency was $4.1 \%$ when approaching through the right internal jugular vein [13]. When the central venous catheter is mistakenly located in the right atrium or the right ventricle, the risk of cardiac tamponade is increased. Collier et al. [14] analyzed 25 cases of cardiac tamponade and reported that the central venous catheter terminal was located at the cardiac silhouette in all cases. Pignotti et al. [7] stated that, if the terminal of the central venous catheter is located at the cardiac silhouette, the location must be verified with chest radiography using contrast media. Reporting that superior vena cava puncture can cause cardiac tamponade, Greenall et al. [5] commented that the terminal of the central venous catheter must not be located at $2 \mathrm{~cm}$ or more below the clavicle.

We have concluded that the central venous catheter was not mistakenly located during the procedure because there was no difficulty in performing the central venous catherization, the blood was well aspirated in the proximal and distal catheters, and the drug injected through the central venous catheter during the operation was efficacious. In addition, patient symptoms, respiratory distress and blood pressure drop, were found after the patient was moved to the ICU, indicating delayed bilateral hydrothorax and cardiac tamponade. It is thought that the bilateral hydrothorax and cardiac tamponade were caused not by endocardial puncture but by puncture of the superior vena cava because the chest radiograph showed that the central venous catheter terminal was located in the superior vena cava, outside of the cardiac silhouette. The puncture was caused when the catheter terminal came into contact with the superior vena cava wall due to formation of a loop caused by the central venous catheter. In cases where the central venous catheter contacts the venous wall or the degree between the blood vessel wall and the central venous catheter is larger than $40^{\circ}$, the possibility of puncture is increased by the erosive damage and necrosis of the intima $[1,3,10]$. Tayama et al. [3] reported that punctures can be caused when the central venous catheter terminal comes continuously contacts the superior vena cava wall Jiha et al. [10] mentioned that the possibility of puncture is low when the degree between the blood vessel wall and the central venous catheter is less than $40^{\circ}$ because they are parallel, but the risk of puncture increases as the degree becomes larger. Leech et al. [15] stated that a puncture is more probable if the central venous catheter terminal located in the heart is in contact with the cardiac wall because the catheter terminal moves in correspondence with the motion of the diaphragm, neck, and face due to heart motion and respiration. It is also known that the hyperosmotic fluid used for total parenteral nutrition can cause blood vessel puncture through erosive damage $[3,4,11]$. A high calorie count or lipid drugs 
have the potential to damage the intima because of osmotic pressure difference, which can then cause dislocation of the catheter from the blood vessel through the damaged intima. Particularly in the case of the patients who are treated with steroids, glucocorticoid can weaken the blood vessel wall with increased risk. Ellis et al. [11] stated that when the catheter terminal is located in the central vein, hyperosmotic fluid can be diluted and safely injected with the help of rapid blood flow. However, when the terminal is located near the blood vessel wall, chemical as well as physical factors can damage the intima. The materials of the central venous catheterpolyethylene, silicon, and polyurethane- also have an effect, with. The most common cause of thrombus and phlebitis being polyurethane followed by silicon and polyethylene [2]. The stiffer the catheter, the higher the risk of puncture consequently, polyethylene catheters cause the most blood vessel punctures $[2,6]$. The central venous catheter used in this case report was polyurethane, the least dangerous, but its loop inside the blood vessel may have cancelled out the material advantage.

Stimultaneous occurrence of bilateral hydrothorax and cardiac tamponade is very rare [6], and the cause is not clearly understood. Pignotti et al. [7] reported a case of simultaneous occurrence of bilateral hydrothorax and cardiac tamponade where the central venous catheter was located in the right atrium of an infant. They assumed that bilateral hydrothorax caused it because the fluid entered into the pericardium through the atrium wall damaged by a direct atrium puncture or by the action of the hyperosmotic fluid, and flowed out to the mediastinum. Haass et al. [8] reported a bilateral hydrothorax and cardiac tamponade case where the central venous catheter terminal was located at the outside of the right atrium. Presuming that the puncture of the superior vena cava wall was cause by erosive damage of the hyperosmotic fluid, they commented that special care should be given when injecting hyperosmotic fluid into a low-weight infant. Simmons and Henderson [9] also reported a case of simultaneous occurrence of bilateral hydrothorax and cardiac tamponade, which was found within 24 hours in a patient with central venous catherization through the right subclavian vein. They assumed that the catheter located at the right internal mammary vein penetrated the venous wall, which was weakened by hyperosmotic fluid flowing out to the mediastinal, causing cardiac tamponade and bilateral hydrothorax by hydromediastinum. Giacoia [6] reported a case of bilateral hydrothorax and cardiac tamponade where the terminal of the catheter was located in the right atrium. Though the cause was not certain, they assumed that the bilateral hydrothorax was caused by fluid possibly flowing out to the mediastinal and both sides of the thorax because of the destruction of the intima due to the catheter or hyperosmotic TPN; The other possible cause was that lymphatic occlusion was caused by a thrombus in the superior vena cava or the branched blood vessels. In this case report, we assume that the superior vena cava puncture was caused rapidly because the central venous catheter, initially forming a loop in the superior vena cava, continuously rubbed against the blood vessel wall, while the hyperosmotic fluid injected for postoperative TPN cased erosive damage to the blood vessel wall. In addition, when trying to aspirate the blood through the central venous catheter in the postoperative ICU, blood was aspirated only through the proximal lumen, not the distal lumen. We therefore assumed that the central venous catheter was dislocated, penetrating the blood vessel but not reaching the location of the proximal lumen of the central venous catheter, and placed in the mediastinum, eventually causing the bilateral hydrothorax and cardiac tamponade.

To verify the abnormal location of the catheter and the blood vessel damage, it is important to check the blood aspiration through the catheter and take a chest radiograph after the procedure $[4,11]$. In order to verify this immediately after the procedure, the normality of blood aspiration through the catheter and the waveform of the central venous pressure should be checked [1]. In the case of long-term catheter installation, it is recommended to take chest radiographs to check the location of the catheter and the occurrence of any complications while at the same time, verifying blood aspiration through the catheter $[1,7]$. Though we verified loop formation of the catheter terminal in the superior vena cava, we were unable to prevent the complication because it was not expected that the looped catheter would cause erosive damage to the blood vessel. The complication was able to be recognized and treated through continued postoperative chest radiographs however, differential diagnosis was too late to find the pleural effusion and hydrothorax caused by pneumonia (the patient's underlying disease), when the respiratory distress occurred. If the effusion fluid had been aspirated and tested early, the possibility of blood vessel puncture could have been recognized and proper treatment, such as removal of the catheter, could have been done earlier. Therefore, in cases where unexplainable cardiovascular abnormalities including respiratory distress or reduced blood pressure as well as pleural effusion are found in a patient with a central venous catheter installed, proper measures, such as chest radiography for diagnosis, should be taken and the possibility of abnormal catheter location and blood vessel damage should be considered. If abnormal catheter location or loop formation is found, it should be immediately corrected. Further, the possibility of cardiac tamponade must be considered when cardiovascular abnormalities such as seriously low blood pressure and tachycardia are found in patients with hydrothorax by central venous catherization. 


\section{References}

1. Tilak MD, Proctor SM, Donovan JF Jr, Fitch JC. Extravascular placement of a central venous catheter in the mediastinum. J Cardiothorac Vasc Anesth 2004; 18: 75-7.

2. Ishibashi $H$, Ohta $K$, Ochiai $T$, Kaisan $T$, Ishikawa $T$, Kubota $T$, et al. Delayed hydrothorax induced by a pericutaneous central venous catheter; report of a case. Kyobu Geka 2002; 55: 213-5.

3. Tayama K, Inoue T, Yokoyama H, Yano T, Ichinose Y. Latedevelopment of hydrothorax induced by a central venous catheter: report of a case. Surg Today 1996; 26: 837-8.

4. Paw HG. Bilateral pleural effusions: unexpected complication after left internal jugular venous catheterization for total parenteral nutrition. Br J Anaesth 2002; 89: 647-50.

5. Greenall MJ, Blewitt RW, McMahon MJ. Cardiac tamponade and central venous catheters. Br Med J 1975; 2: 595-7.

6. Giacoia GP. Cardiac tamponade and hydrothorax as complications of central venous parenteral nutrition in infants. JPEN J Parenter Enteral Nutr 1991; 15: 110-3.

7. Pignotti MS, Messeri A, Donzelli G. Thoracentesis in pericardial and pleural effusion caused by central venous catheterization: a less invasive neonatal approach. Paediatr Anaesth 2004; 14: 349-51.

8. Haass C, Sorrentino E, Tempera A, Consigli C, De Paola D, Calcagni $\mathrm{G}$, et al. Cardiac tamponade and bilateral pleural effusion in a very low birth weight infant. J Matern Fetal Neonatal Med 2009; 22: 1379.

9. Simmons TC, Henderson DR. Bilateral pleural and pericardial effusions because of mediastinal placement of a central venous catheter. JPEN J Parenter Enteral Nutr 1991; 15: 676-9.

10. Jiha JG, Weinberg GL, Laurito CE. Intraoperative cardiac tamponade after central venous cannulation. Anesth Analg 1996; 82: 664-5.

11. Ellis LM, Vogel SB, Copeland EM 3rd. Central venous catheter vascular erosions. Diagnosis and clinical course. Ann Surg 1989; 209: 475-8.

12. Schroeder RA, Barbeito A, BarYoserf S, Mark JB. Cardiovascular monitoring. In: Miller's Anesthesia. 7th ed. Edited by Miller RD, Eriksson LI, Fleisher LA, Wiener-Krinish JP, Young WL: Philadelphia, Elsevier. 2009, pp 1285-97.

13. Schummer W, Schummer C, Rose N, Niesen WD, Sakka SG. Mechanical complications and malpositions of central venous cannulations by experienced operators. A prospective study of 1794 catheterizations in critically ill patients. Intensive Care Med 2007; 33: 1055-9.

14. Collier PE, Blocker SH, Graff DM, Doyle P. Cardiac tamponade from central venous catheters. Am J Surg 1998; 176: 212-4.

15. Leech RC, Watts AD, Heaton ND, Potter DR. Intraoperative cardiac tamponade after central venous cannulation in an infant during orthotopic liver transplantation. Anesth Analg 1999; 89: 342-3. 